\title{
Chapter 2 \\ Early Days: From Personal Awareness \\ to Group Commitment
}

\author{
Jean-Paul Close, Marco van Lochem, Edwin Weijtmans, \\ Mary Ann Schreurs, Alfred Stein, René Otjes and Hans Verhoeven
}

\subsection{A Personal Story of Awareness and Perception}

Chapter 1 develops the historical context of a human world based on economics, trade and consumption mechanisms that evolved into a free and democratic market with political and economic dependencies, rules and relational structures.It shows that we may have reached a dead end as a result of the flaws in this system as they appeared over time up to a level of exponential tension around the world, within the system itself and with our natural surroundings. It concludes by trying to understand the rational and irrational aspects of human group behavior. In essence, this is what it is all about: human beings, their complexity, and the way we manage to progress through time successfully as natural, self-aware, evolutionary, group-oriented creatures. My chapter is therefore dedicated to this wonderful and extraordinary, confusingly evolutionary phenomena, the human species, complex

J.-P. Close (ه)

STIR Foundation, Eindhoven, The Netherlands

M. van Lochem

Odeon, Best, The Netherlands

M. van Lochem

Axians, Eindhoven, The Netherlands

E. Weijtmans

Den Bosch, The Netherlands
A. Stein
Faculty of Geo-Information Science and Earth Observation (ITC), University of Twente,
Enschede, The Netherlands
R. Otjes
ECN, Petten, The Netherlands

M.A. Schreurs · H. Verhoeven

Environment, Eindhoven, The Netherlands 
beings which I have put at the center of our natural attention. In this story, I use one specimen as an experimental guinea pig, myself (Jean-Paul Close), to try to understand what has hardly been understood before, maybe because of our blind focus on external mechanisms of power, control and submission rather than harmony, symbiosis, awareness and life itself. Can this change?

At the time of my return to the Netherlands in 2001, after an expatriated absence of 27 years, none of the analysis described in this book had been part of my own reality. I had never heard of Ostrom and the commons, nor Kazimierz Dabrowski and his layers of the consciousness, or Matthew Lieberman and his brain research applied to human behavior. This whole world of understanding of our complex behaviour and interpretation of things did not exist for me. Why? Simply because I was not aware, just like the great majority of my fellow human beings is not aware. I had grown up in the world of business development, marketing and hierarchical methods of human resource management, profit and loss, personal growth, etc. I had learned to look at my natural surroundings as if it were an oil painting, enjoying the beauty of nature, experiencing moments of emotional pleasure when hearing the waves of the sea, smelling flowers or feeling the warmth of the sun when on holiday. My sensations were that of an eyewitness, an observer, not of a self-aware part of it all, let alone one with the possibility of sensing responsibilities or the need to harmonize with it. My real world was that of business transactions and competitive careers in executive hierarchies. All this was about to change.

Since my birth in the Den Bosch, The Netherlands, in 1958, I had been living in countries that were in a phase of developing their economies and democratic structures. And I was professionally very active in performing and developing a career within these mechanisms. It never even crossed my mind that there could be risks or consequences to this way of working and thinking. My perception of the world first evolved in the post-war Dutch society of the 1960s, in which the public discourse was about social securities, pension schemes, amount of working hours and taking measures that would prevent a society from entering again into a predisposition for public uprising and war. Germany was used as a historical reference while the Dutch society evolved into a "society of caretaking", in which government took over responsibilities from the population with the guarantee of providing wellbeing in exchange for peace.

When I moved abroad at age 16, in 1974, we landed in Barcelona, Spain, where my father had become an expatriate executive for a Dutch multinational. My emotional and rational development evolved further, having to adjust to an English school system populated by the "special breed" of children of ambassadors, executives and scientists, all with a touch of arrogance and financial wealth. Then the Spanish dictator Franco died. This released a tremendous amount of energy and tension for the cause of restoring the lobby for Catalan autonomy, while King Juan Carlos I was assigned to re-establish the local monarchy and national democratic cohesion, originally established by the Catholic Kings in 1492. The subsequent connection with the European Community and the organization of several big events, such as the world soccer championships in Barcelona in 1982 and the Olympic Games and the Expo in Sevilla, both in 1992, caused Spain to enter into its 
own boost of economic development and real estate bubble. In this ever-growing context, and as far as I was concerned, economic growth was a given, I had not experienced anything else yet. My own career also seemed to evolve in an automated process of professional and economic growth, as if this was the most normal pattern, and one that would last forever. However, at this point I started to question this for myself: "Is this all?"

My first encounter with a national crisis came when I was a student of Mathematics and Computer Science at York University in the UK, between 1977 and 1980, at the time of Margaret Thatcher. This crisis was not yet one that entered my consciousness as something that affected me personally, other than the sudden multiplication of the annual tuition fees by three. Margaret Thatcher has been quoted as saying: "If foreigners choose to benefit from the excellence of our education then they have to pay for it." My own subsequent professional career had me working in multinationals with world wide executive responsibilities, ending up, after a period in Stockholm, Sweden, back in Spain again, thanks to my knowledge of the local language. My professional career evolved strongly in the field of European computer and telecommunication networks and technologies.

\subsubsection{My First Awareness Breakthrough}

My first divorce, in 1996, involved my daughter, aged just 18 months. It made me aware for the first time of the inner conflict between moral responsibilities towards my child and the practical complexity of a global executive career. I decided to let go of the latter and develop my professional life around responsibility for the wellbeing of my daughter and harmony with her. The emotional process of voluntarily letting go of all the benefits and status of being a global executive, without any prospect of financial security after the choice had been made, had a deep impact on me. I had to come to terms with my inner turmoil and the chaos that evolved from letting go of the sense of safety and motivation for external material wealth, learning to trust myself as my own security and resource, no matter what.

Something truly astonishing happened to me. At the deepest point of self-pity and sorrow, there was an inner breakthrough. I had stopped in the countryside near Madrid to take some time to come to terms with myself. For the first time, I observed my natural surroundings with a new sense of harmonic connection, seeing it as a totality of which I was a living and self-aware part. I could sense the colors of the trees and the sky, the flying of the birds and warmth of the sun. None of this had ever broken through into my conscious awareness before, while travelling from hotel to hotel, city to city, airport to airport, as if this reality had been hidden from my senses due to some programmed way of living life. Having gone through the extremely painful experience of letting go and opening up to the realest of realities, a totally new world had suddenly opened up for me. It felt like a revelation. I was not a witness or observer any more; I had become part of it all. This was 1996, and it would mark my life ineradicably from that moment on. 


\subsubsection{Layers of Awareness}

Many years later, I would learn about the theory of the layers of awareness, the levels of positive disintegration, described by psychologist Kazimierz Dabrowski, ${ }^{1}$ and the effects of mental growth through these experiences. Dabrowski and subsequent analysts of human behavior describe 5 layers of awareness that all have to do with the "letting go" (disintegration) and the revelation of new levels of deeper insight (integration). Later, I would start adding my own experiences and analysis to the insight, but at that moment, it had become a delight to learn about the working of the conscience, an idea from which I had previously mentally blocked myself when I concentrated only on personal growth in a competitive environment. Stated plainly, "empathy" is a psychological state that requires people to go through a sufficient process of disintegration so as to become capable of understanding and valuing the pain or beauty of another. Curiously, analysts state that only a small minority of people reach that state of awareness, while the vast majority remains stuck in the lowest two levels, just worrying about competitive growth (I want a bigger car than my neighbor's) and survival (as long as I can pay my mortgage and go on holiday twice a year) without even sensing other issues at hand. This could explain why the human world has such difficulty responding to climate change, pollution and the many other global issues. We observe it as witnesses, as outsiders, so that it does not reach our inner selves, so that it does not affect our daily routines and choices around short term self-interests (Table 2.1).

Interestingly, we can consider that our personal and individual human development may reach level 5 of understanding of the genuine principles and complexities of life. We do this through structural processes of letting go, with awareness breakthroughs emerging out of our own mental chaos. But our organized structures, such as government and business, have historically evolved only to levels 1 and 2, disintegrating completely in conflict and chaos while showing an extremely slow capability for breaking through into collective awareness. In my perception, we have been struggling collectively to let go of levels 1 through 3 for over 5000 years now, having structured society around egocentric greed, hierarchy and control ever since structures were needed. Levels 4 and 5 may now lay ahead of us, possibly producing an historical breakthrough and evolutionary leap for our species. This is where I position this documented exercise, as an invitation for people and institutions to join together into a totally new and deeper societal reality.

Soon, my own world, within the energetic positioning of the administrative and political center of Spain, Madrid, evolved again in the development of my own financial security. The next few years were rollercoasters for me, veering between the external and inner securities of extreme entrepreneurial success and financial growth, sudden collapse and rebuilding the cycle all over again. As a consequence, my emotional views of economic reality and the working of the markets became intensified with empiric experiences that I, at the time, could not yet rationalize or describe as was done in part one, above. The collapse of the internet bubble in

\footnotetext{
${ }^{1}$ Dabrowski, Kazimierz, Andrzej Kawczak, and Michael M. Piechowski. Mental growth through positive disintegration. London: Gryf Publications, 1970.
} 
Table 2.1 Dabrowski levels of disintegration and integration compared to J.P. Close cyclic complexity

\begin{tabular}{l|l|l|l}
\hline No & Dabrowski level & $\begin{array}{l}\text { Dabrowski } \\
\text { characteristic }\end{array}$ & Jean-Paul Close characteristic \\
\hline 5 & Secondary integration & Harmony & $\begin{array}{l}\text { Harmonic wellbeing and co-creative } \\
\text { action }\end{array}$ \\
\hline 4 & $\begin{array}{l}\text { Organised multilevel } \\
\text { disintegration }\end{array}$ & $\begin{array}{l}\text { Self } \\
\text { organisation }\end{array}$ & $\begin{array}{l}\text { Awareness breakthrough and personal } \\
\text { action }\end{array}$ \\
\hline 3 & $\begin{array}{l}\text { Spontaneous } \\
\text { multilevel } \\
\text { disintegration }\end{array}$ & Ideal versus real & $\begin{array}{l}\text { Awareness development (doubts } \\
\text { between what is right and wrong) }\end{array}$ \\
\hline 2 & $\begin{array}{l}\text { Unilevel } \\
\text { disintegration }\end{array}$ & Conflict & Competition and chaos \\
\hline 1 & Primary integration & Self-gratification & Growth \\
\hline 0 & Not defined & Not defined & Conception (=5 from previous cycle) \\
\hline
\end{tabular}

$2000^{2}$ meant the definitive end of an era for me as a telecom professional. In just one month, two of my major contractors and sources of income went under. It became clear to me that I would have to open up to new realities, including professionally. I also became more clearly aware that life does not consist solely of phases of growth and conflict. There is much more to it and I was determined to figure it all out. But first, I had to modify and adjust my own life's patterns.

I decided to move back to Holland with two motives:

- I perceived the Netherlands as the geographical center of executive Europe from a regional multinational point of view, creating better perspectives for a future for someone with my executive profile;

- I wanted my children, the second one of whom was on her way, to have the benefit of the sort of multicultural foundation I had enjoyed and valued as important, including the Dutch culture.

\subsubsection{My Second Burst of Awareness}

Upon arriving back in the Netherlands, after the already-mentioned absence of 27 years, I was immediately struck by the intense culture changes that had taken place in my country. At the time of my departure in 1974, there had been a sense of national unity of purpose, a shared vision of a new society striving for social justice and peaceful fulfillment of the material and immaterial needs of every citizen. What I found, however, was a harsh money-driven, consumption-orientated and

\footnotetext{
${ }^{2}$ Fransman, Martin. Telecoms in the Internet Age: From Boom to Bust to? Oxford University Press, 2002.
} 
speculative culture, with a tremendously bureaucratic and prejudiced, even discriminatory, government wielding its clumsy and insensitive regulations. This was not the country that I had been returning to in my mind.

Never, anywhere in the world, had I encountered problems finding housing for me or my family. In the Netherlands, there was a waiting list of 5 years for a social rental home. Options were available in the free rental market, but this was at extreme prices adjusted to the expat market of temporary housing, not the rootless people "coming back" after an economic crash in the world of expats. Another option was to purchase a house. This was conditioned on the collateral of indefinite labor contracts and extreme prices that had been manipulated in the real estate boom since the '70s. A house that was purchased in 1970 for the equivalent of $€ 15,000$ would sell in the year 2000 for $€ 250,000$. Paying for the house four times (the original price and the equivalent of 30 years interest rates at $7 \%$, representing a doubling rate of 10 years!) still left a perceived profit (not real, because the profit is relative to the past not the present) of $€ 190,000$. What justified this huge value increase? What justified the extreme profits of the banks? Banks would draw the same line into the future to justify their $120 \%$ mortgage offer against $5 \%$ interest. The same house would be worth, according to them and the common belief, 3 million $€$ in 2030. It became clear that such economic bubbles of perceived enrichment, without doing anything in terms of productivity, and an unnatural 30 year mortgage claim against future labour, had become a common problem of collective blindness, including mine. But where can I live with my family if the environment is as harshly manipulated as it is? We had no choice. We bought a house.

My second boost of awareness came when my family, consisting of 5 individuals, 2 adults and 3 children, had to apply for residence permits on an individual basis, regulated by the system's bureaucracy. We were not treated as a family, while in "my world," a family would be considered the basis of society. Government reasoning was related to the level of abuse by people entering the country and enjoying the socio-economic benefits through fake marriage arrangements. My second wife was Brasilian. Each family member was emotionally tormented by the possibility that one or more members of our family would not be allowed to remain in residence. This caused so much fear and insecurity that the family cohesion started to suffer. My wife was forced to "integrate" into the Dutch culture, valued against materialism, language and having access to the labor market, rather than developing her perception of ethical value: family cohesion. The Dutch demands were contrary to her and my cultural beliefs of family harmony. The system's push was sensed as inhumane, immoral and unjust. She felt so much stress and aggression against her own inner values that she reacted back with aggression within the family, with natural evasive behavior of escapism.

After one year, the stress had become so great that the family union broke up. I had to take instant responsibility for my children by going into hiding against the aggression. My wife fled the country, leaving me to carry on as a single father for the children within a totally disrupted community. We lost our house, our income and stability. Thanks to the help of family, I was able to survive, but the 
general overall governance culture necessitated that I again become a participant in the tax-paying community, subcontracting, if desired, the stability and education of my offspring to the system for the sake of money. We were made marionettes in a money-driven reality. If I refused, I was not provided access to social security; if I agreed, I needed to accept the vulnerability of my children in the face of possible abduction.

I refused.

This is not the type of society that I want to pass on to my children.- J.P. Close (2005)

My first burst of awareness had made me aware of my deep inner sense of harmony with my surroundings and my responsibility for living life, trusting my abilities instead of blindly following external securities and rules. My second burst of awareness reconfirmed this and made me conscious of society as a simple (no matter how complex) set of rules measured against a diversity of possible values that can go from human securities and cohesion (post-war development) to trying desperately to sustain an artificial system (money) at the expense of what it was built for in the first place. My second boost of awareness was related to the way communities develop and change "polarity" from cohesion to greed, from unity to falling apart. My awareness, as experienced at the level of family cohesion, could also be applied to the larger community. It became clear to me the way in which group patterns appear, growing up to a limit and then tending to collapse when they reach a certain point (point of singularity - see Fig. 2.1). It dawned on me that this happened in living nature all the time. In my personal view, Dutch society was on

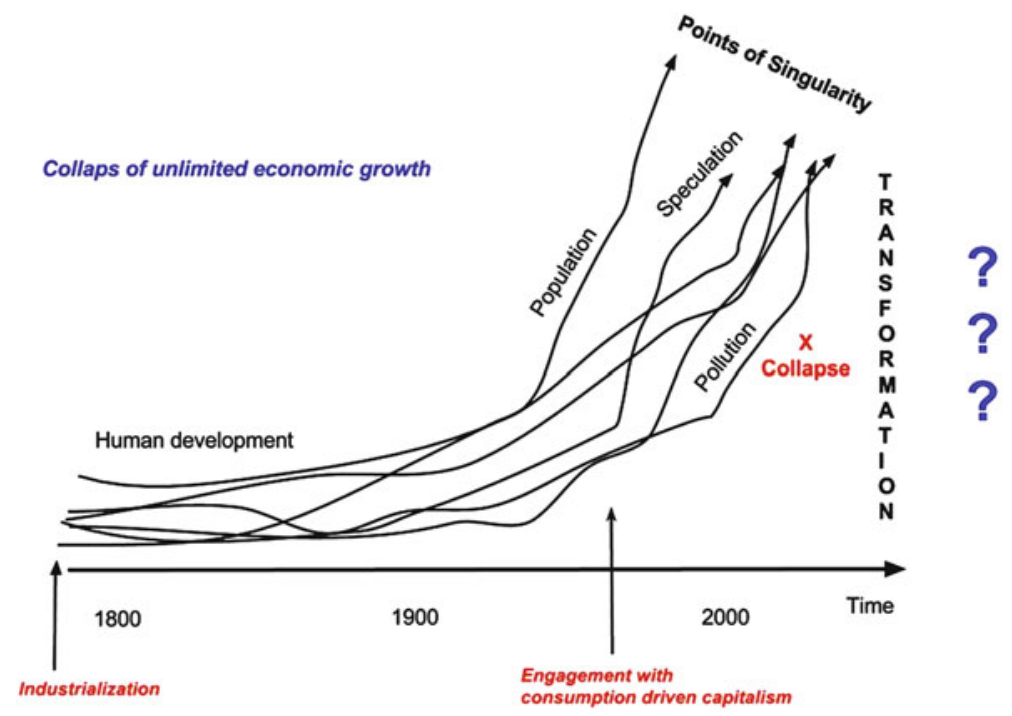

Fig. 2.1 The engagement with consumption driven capitalism produced the misconception of seemingly unlimited economic growth 
the verge of collapse, sustaining itself only through artificial measures of inhumane proportions. It had grown from a social democracy into a self-imposed financial dictatorship. I did not feel part of this and was surprised that the population did not react. The situation could not last, because it lacked all sense of community. Why was there so much blindness? Why so much apathy? People only complained. Why so much dependence? Why so much fear?

One of the interesting consequences of a second positive integration described by Dabrowski is the gradual disappearance of "fear" as deeper awareness connects with the essentials of life and the harmonic connectivity with social and natural resources. No fear is needed. One learns to possess nothing so there is no fear of losing anything. One becomes humble, free and fearless. Ironically, for those competing in life this humbleness is seen as a weakness, while in reality, it is the most powerful and lasting of all layers. All points of singularity feared by so many then become obvious turning points, starting points of a new beginning, not a fearful dot to be avoided all times, but one to be cherished as essential for life renewal and evolution. While the entire world was either blind to this or trying to avoid collapse, I found myself engaged by motivation, joy and determination to define "What's next?"

\subsubsection{Defining a New Society for Myself}

My own sinusoidal life pattern resembled the cyclic wave analogy described by economist Kondratiev. ${ }^{3,4}$ It could even be related to the work of Pythagoras and Galileo Galilei on musical patterns. ${ }^{5}$ Musical strings contain a secret that explains patterns of life that can be traced into the formation of huge constellations all the way down to the positioning of planets in relation to their solar system, the way our weather behaves and the alliance of molecules to form life and evolve through DNA strings. For the first time in my own life, I could observe the uniting powers of harmonic rhythms in nature, the fractal growth patterns in life, including the phases of collapse and the analogy in economics, group dynamics and business development. All this knowledge and awareness was a personal privilege that became difficult to share with others. What had become very real for me was abracadabra for nearly everyone else. When I started talking about it, my audience's attention would fade quickly, rapidly reverting to their daily issues. They would admire and acknowledge my fearless single fatherhood and the perceived challenges this

\footnotetext{
${ }^{3}$ Goldstein, Joshua S. "Kondratieff waves as war cycles." International Studies Quarterly (1985): 411-444.

${ }^{4}$ Rainer, M. E. T. Z. "Empirical Evidence and Causation of Kondratieff Cycles." Kondratieff Waves, Warfare and World Security 5 (2006): 91.

${ }^{5}$ Walker, D. Perkin. "Kepler's celestial music." Journal of the Warburg and Courtauld Institutes (1967): 228-250.
} 
brought me, but not the reasoning behind it. Nor did people understand that I was busy and highly motivated all day, and every day, but did not "work" for a boss.

The mainstream human's reality was based on external material securities, managed through a competitive system of labor dependence and status that still had a strong relationship with the old industrial era. Work and living life were seen as two different things, a dual inside and outside system which perhaps clarified why people might see their family life as something separated from society. The fact that I considered family life and my contribution to society as being the same thing meant that I perceived "human values" in a different way than those surrounding me. They calibrated family life against the level of income generated by this other life, called "work". One either had work or not, receiving an income either out of labor or social security. The binary switch between work/no work was just income-, activity- (to Do) and status-related, it did not challenge people to open their minds to broader realities (To Be). The "To Do" and "To Be" entered my curiosity (Fig. 2.2).

None of the above experiences would have entered into my awareness either if I had not returned to the Netherlands to witness the dramatic change that had taken place between 1974 and 2001. I would have mainstreamed my life like anyone else. Now, it had reached my understanding in all its complexity and it had a huge impact on me. Even my return to Holland at age 43 after an absence of 27 years could be placed along the cycle of the musical resonance and the vibrating string theory of nearly 54 years, equivalent to a full Kondratiev cycle and the famous 7 + year sub-cycles of ups and downs. Was this casual? Or part of my own life's pattern within a much larger symphony of patterns that we are normally not aware of? What significance does "harmony" have as opposed to growth? What role does money have in all this and human awareness? Is harmony the status quo or hard work? If I can realize how it works for one single human being, with all their moments of stress, pain, new awareness and new phases of inner and external harmony, how will it work when we consider masses of individuals in a lump sum?

A new world of investigation had opened up to me.

Fig. 2.2 The way we tend to perceive ourselves, influenced by society's rules and culture

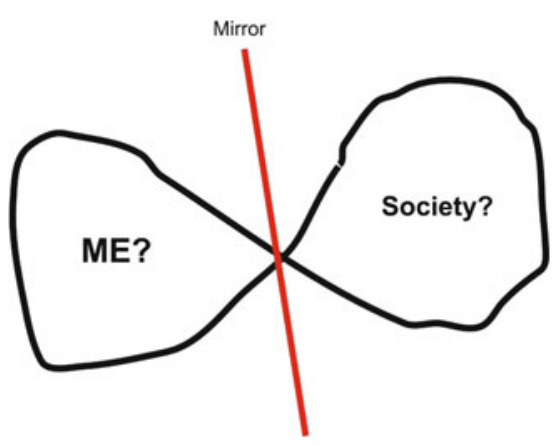




\subsubsection{Key Human Values}

In my own two different occasions of boosting of awareness, I had to make my own mind up about ethics and responsibilities without relying on rules and regulations. My mind had opened up to see that the ethics of the societal system that demands solidarity with economics and social security is totally different from the ethics and sense of responsibility that nature imposes upon us. On both occasions, I reasoned that neither status nor employment is relevant to a good life if it comes at the expense of our future generations. What would you save first in times of war? Yourself and your children, or your possessions?

In our dual lives (work and life) we had separated responsibilities, developing our own at home and letting governance take care of the rest. The common denominator had become "money dependence" and not our key human values.

It became clear to me that, as individuals and as a society, we had inverted our priorities. Key values of human evolution can neither be delegated nor purchased. They represent responsibilities that we carry alone and together. Responsibility cannot be expressed in money, nor can life, which is too valuable. The true human values resonate and create cohesion and commitment; if neglected or destroyed, they cause communities and life itself to fall apart. This is how I had experienced it in my own life's evolution.

From my new point of view and awareness, the analogy of musical bonding, that keeps constellations or molecules together in living patterns, applies to societies too, starting at the family level and expanding into the entire community, including the meaning and operational reality of institutions. Recently, I looked back at my inner discoveries, motivated by the writing and editing of this book, and came across the work of brain researcher, Dr. Matthew Lieberman. ${ }^{6}$ He explains in an impressive TED talk that "Abraham Maslow's hierarchy of needs" was wrong. The first basic essential of every human being is social cohesion, not the fulfillment of our primary material needs (Fig. 2.3). ${ }^{7}$

This simple remark, which I called "the Lieberman correction," has huge consequences if taken to heart in establishing communities and societies. Today, we organize ourselves around the idea of ensuring the abundance of basic needs in a consumption-driven society. When people have what they need, then there is no more need for social interaction. And even worse, when people fear losing what they need in such a caretaking consumer environment, the psychological tendency is to avoid social interaction even more or become aggressive towards one's surroundings in a primary reaction of defending self-interests (hoarding). We take the liveliness and creative purpose away from the individual and the community,

\footnotetext{
${ }^{6}$ Ochsner, Kevin N., and Matthew D. Lieberman. "The emergence of social cognitive neuroscience." American Psychologist 56.9 (2001): 717.

${ }^{7}$ Rock, David. "Managing with the brain in mind." Strategy + business 56 (2009): 1-11.
} 


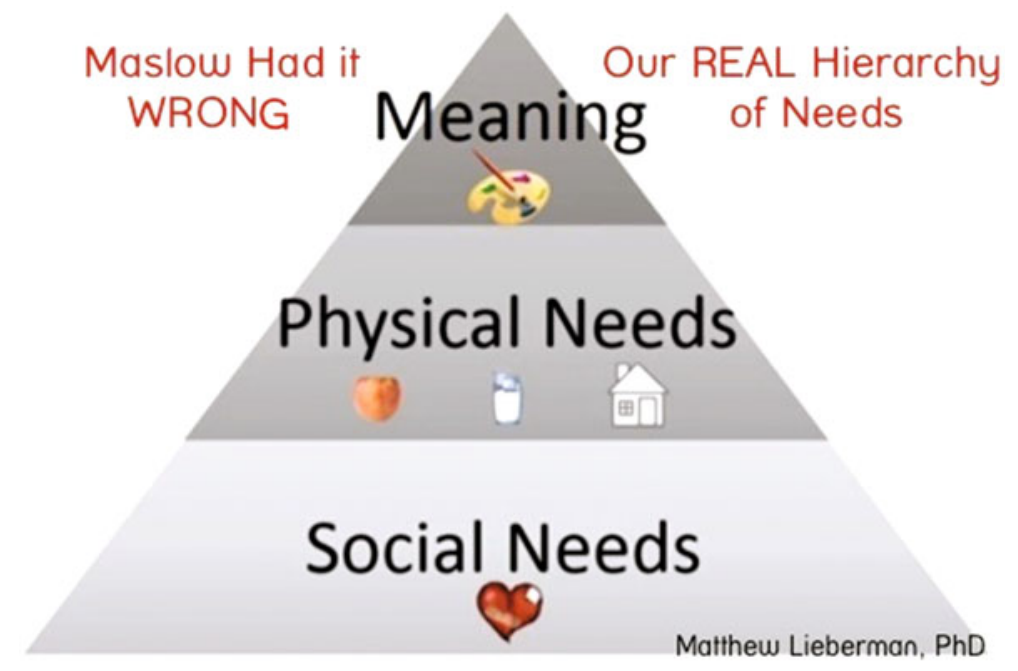

Fig. 2.3 Dr. Matthew Lieberman, Maslow was wrong

resulting in an unproductive "frozen ego" 8 type of situation. If we wanted to revert back to key human and evolutionary values, I would have to rephrase society around such importance of cohesion:

- Society needs to collectively respect and facilitate human values, such as health and safety, above political and economic interests, just like we do on the family level;

- Society needs to engage in harmonization of our human and natural surroundings by taking proactive responsibility instead of delegating it into a remedial system.

My personal decisions in 1996 and 2003 had been intuitively done with this in mind. Now, I learned to interpret and rationalize it, with important references all the way back to the times of Pythagoras. Apparently, we had needed 2500 years of societal trial and error at the collective levels 1 and 2 of Dabrowski's 5 layer awareness scale to reach a collective point of singularity of blind unethical growth, to subsequently crash and open up to the levels of collective positive disintegration rather than just the individual.

\subsubsection{Inside $=$ Outside}

I had felt that the key responsibilities of any self-aware adult human-being towards their own selves and the children in their home should remain the same when

\footnotetext{
${ }^{8}$ Close, JP (2013) "Frozen ego's" when apathy takes motivation away to do something other than complaining.
} 
stepping outside the front door. Why should the priorities in society differ from home? Did my own consciousness differ from that which surrounds me? And what did I need to do to establish the synchronicity? Accept the situation that got me as part of a family union into trouble and adjust my commitment to life to that which was imposed on me by a "wrong society"? Or should I apply the lessons of life learned and try to introduce a new practical reality based on the productive energetic patterns of harmonic or symbiotic relationships? I decided that the latter gave me a better sense of purpose, as I could take responsibility both for my choices at home and in the development of my professional or social activities outside.

My inner quest became to understand why groups of people connect and come alive in productive communities, such as families, a business community or entire societies, and what makes them fall apart again in crises, recessions, bankruptcies, divorce or confrontations. What could I learn from nature and apply to society? A new experimental world in which I could look for answers had revealed itself. And I was not alone. This process was and is happening all over the world. The Ostrom experiments described in Chap. 1 are a clear example, but our complexity is much larger than a bunch of individuals. Theory is now abundantly available, but putting it into practice is severely handicapped by many influences and a lack of leadership.

\subsubsection{To Be and To Do}

In 2005, my trust in government was less than zero due to the way it had treated me and my family, and the painful consequences we had suffered. A local government should protect and enhance local values, never become a danger itself to its community and surroundings. In hindsight, I am now grateful, because it had opened my eyes to a diversity of realities, and it had also opened my mind to intense complexities and tensions that could be explained by natural psychological patterns of conservatism and managing security, alternating with forceful or voluntary periods of leadership and intense change. In 2005, the overall national pattern was focused on economic growth with a strong democratic push to conserve social securities and a local perception of wealth. There was no overall sense of need for change in the country. Any reference to the lack of symbiotic resonance, broken harmony and risk of crisis was waved away. So how did my personal breakthrough relate to what I wanted for the country?

When I was invited by my friend Prof. Paul de Blot ${ }^{9}$ (Business Spirituality) to give a guest lecture at the Business University Nyenrode, a new puzzle piece fell in place. Paul explains human awareness development along two lines: that of what one does (To Do) and that of what one learns as a consequence, developing what one is as a person (To Be). There is an element of trial and error. We experiment

\footnotetext{
${ }^{9}$ Prof. Paul de Blot-Nyenrode http://www.pauldeblot.nl.
} 
with our actions and interpret the results. That's how we learn to value our senses, distinguish between safety and danger, remember things and proceed with new experiences. Our earliest concerns when born are food and protection. When we grow up, we encounter competition with others while in search of our genuine selves. We enter into conflicts, win and lose, getting to value both, up to a point that we learn to avoid conflict by enhancing what we are, the uniqueness and authenticity that needs no conflict. We then establish harmonic relationships to have children of our own. It is a natural process (Fig. 2.4).

In our discussions, I presented my own view of an inner breaking point, the turning point when To Be starts to lead To Do. While we are growing up through trial and error (we do and learn to be), we may encounter a unique moment of inner revelation after which the trial and error disappears and we develop a creative type of empathy with our surroundings and the need to harmonize. When we do things, we do them with a harmonizing reason. We start to contribute instead of just take.

My own focus on creating harmonic relationships and shaping communities had to find a productive way forward. I had lost confidence in my fellow citizens, whom I found to be blind consumers and workers without any notion whatsoever of consequences, and their own democratically chosen government, dedicated to fulfilling that public desire while raising taxes to remediate the damages. So I developed my transformative mission in the only remaining area where I could try to find enough ground to make a difference: business development. I started coaching businesses and business transitions. In entrepreneurship, I still hoped to find real potential to change society through innovation. Just think of the effects on society of microcomputers, software and the appearance of the Internet. Maybe I too could pull enough entrepreneurial strings to make a breakthrough somehow (Fig. 2.5).

Fig. 2.4 Our natural self-learning process through trial and error

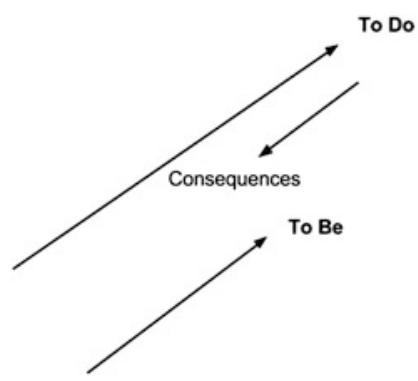

We learn through backwards interpretation 


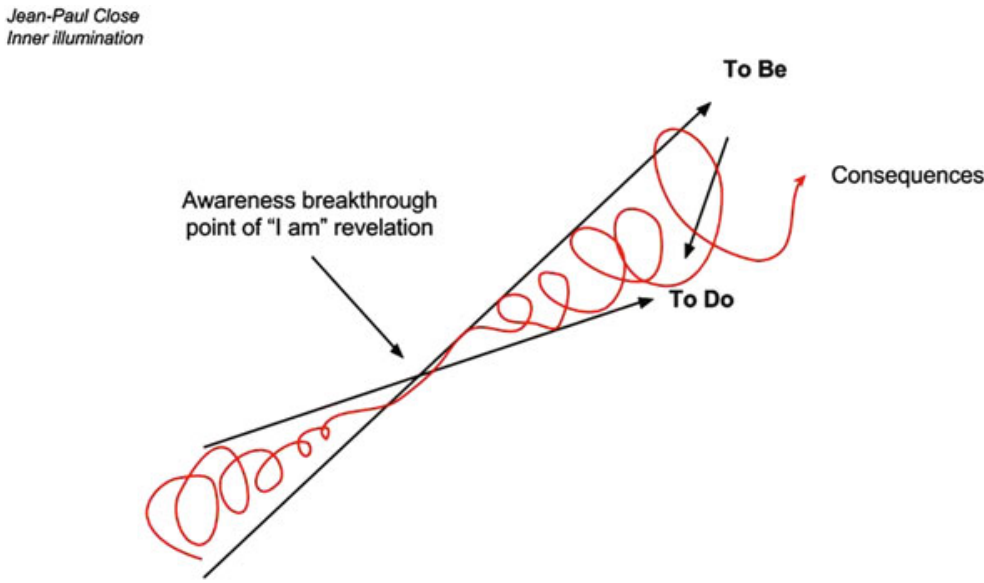

We evolve through forwards interpretation

Fig. 2.5 The awareness breakthrough point defined by Jean-Paul Close

\subsubsection{Welfare or Wellbeing?}

If I wanted to understand my own inner development and learning processes, I realized I had to write them down and share them with my surroundings. Having arrived at my own insights about the harmonic and symbiotic relationship with my surroundings, how would I apply this to positioning a type of entrepreneurship? Having studied International Business Studies at Nyenrode in The Netherlands, completing two Spanish masters' degrees in marketing and business management, respectively, and after multiple business initiatives of my own, including the one that earned the denomination of Best Business Idea of the Year in the '90s, I had a pretty good idea of the evolution of business over the years, especially since the beginning of industrialization in the 18th century in the UK, as well as pre-industrialized processes and trade in the Netherlands since the 15th and 16th centuries. In fact, a clearly differentiated pattern appeared between the way welfare developed through speculative risk-taking in competitive trade channels with commodities and luxury goods and the planned symbioses with which farmers produced basic human needs in close relation with nature and the seasons. The Dutch developed a golden age around speculation, establishing risky trade with the entire world, especially Africa and the Far East. It is interesting to see the two different worlds of entrepreneurial success expressed in semantics. The Dutch language has two words that, in essence, mean the same thing: "to be successful". They translate as follows, both having totally different backgrounds and underlying reasoning: 
- Welfare: as in "welvaren," the Dutch word for wishing sailors a safe and successful trade journey, similar to the hunting groups of the ancient tribes who risked their lives and health to hunt for food. "Welvaren" means literally 'good sailing.' A person who is referred to as "welvarend" is considered rich and successful.

- Wellbeing: as in the Dutch idiom "goed boeren," meaning the finding of a balanced and cyclically productive relationship with the natural surroundings for food production. "Goed boeren" means literally 'good farming.' A person who is referred to as "boert goed" is equally considered rich and successful.

In all societies, we still find both lines of thinking in the development of the countryside and the way people interact with each other. Since the process of industrialization, the entire business industry had developed around fragmented expressions of welfare, measured in financial benefits, not in wellbeing. Trade, speculation and industrial productivity had a natural attraction for people who also desired to consume the luxuries that were produced. It became the impulse for the development of cities in which dynamics of logistics, industrial productivity, profit, infrastructure, growth and the availability of skilled labor were key factors for competitive success.

At the end of the 18th century, pollution in cities was so serious and the mortality among the working force so high that governance was needed to try to establish the wellbeing required to sustain a living community rather than a dying one. The first constitutions were formulated to address such imbalance by introducing rules, regulations, bureaucracy, compulsory education and controls. Welfare and economic growth remained dominant, while wellbeing became a reactive, remedial second priority. As globalization has evolved, we see that the tension between welfare and wellbeing has grown to unsustainable proportions. We now realize that we need to turn those priorities around by putting wellbeing first, with welfare as a sub-system that sustains the development of wellbeing. This turnaround would normally be done through a natural process of collapse. I had proposed a voluntary process of awareness development, breakthrough and self-organized transformation. This became my personal mission. "To Be" (wellbeing) had to start leading to "To Do" (welfare), at the societal level as well. Was society approaching the afore-mentioned breakthrough point?

\subsubsection{Business Transformation}

In 2005, the early signs of a forthcoming (economic) collapse were clear but found hardly any ground for structural attention, as welfare mechanisms were still booming. Trying to act with some expectation for a positive result, I placed my focus on change by redefining entrepreneurship. I summarized the (r)evolution of business as:

The business transformation from using the planet and people for financial benefits (welfare) into serving the planet and people for sustainable human progress (wellbeing). 
This change was characterized as the evolution of business spirituality ${ }^{10}$ of the 21 st century and resulted in the 5 keys for business success ( $5 \mathrm{~K}$ method), published in $2005^{11}$ and 2008. ${ }^{12}$ The term "business spirituality" often confuses people who relate "spirituality" to some sort of metaphysical dimensions or religious dogmas. Spirituality in this sense refers solely to the search for inner meaning of an entrepreneurial mission, a purpose that is powerful enough to connect the people participating within a level of creativity and productivity that goes beyond that which one would expect from them. The Business University of Nyenrode had a chair studying this, and these ideas brought me back in touch with Professor Paul de Blot.

The major change envisaged for business development was the challenge of taking entrepreneurial responsibility when addressing the global issues that concern us as a global community. Examples of those issues are carbon dioxide emissions, climate change, pollution, destruction of landscapes, huge migrations, financial manipulation motivated by greed, speculation, destruction of natural resources, etc. (Fig. 2.6).

As I worked as a consultant and coach during those years, I realized this particular entrepreneurial ideology could be tested in the boardrooms of many local and multinational organizations. Various business plans were subsequently written with the use of the $5 \mathrm{~K}^{13}$ and $4 \times$ profit $^{14}$ methods as sources of inspiration. The money-driven resonance in the executive boardrooms of the businesses that I coached was, however, taking most of the attention away from the key values that authenticated the original business proposition at its conception. Speculative growth (welfare) and survival (competition) prevailed over symbiotic content (contributing to wellbeing), placing the organizations in short term aggressive battles for survival with hardly any long term vision. A $5 \mathrm{~K}$ based indexation study of over 300 enterprises in the Netherlands in 2007 revealed two interesting conclusions:

1. Enterprises born after 2000 were much more aware of servant needs, positioning themselves much more strongly in the field of responsibility for wellbeing and co-creation than the older companies that concentrated on speculative welfare and self-centeredness.

2. The overall average of the business indexation of the analysis was a " $\mathrm{C}$," meaning that business in general did not contribute to the welfare development of the Netherlands anymore, despite its focus. Global speculative competition

\footnotetext{
${ }^{10}$ Wilber, K. (2001) A theory of everything: An integral vision for business, politics, science, and spirituality. Shambhala Publications.

${ }^{11}$ Close, J-P. (2005) Handboek voor de (toekomstige) Marktleider.

${ }^{12}$ Close, J-P. (2005) Succesgids voor Ondernemers.

${ }^{13} 5 \mathrm{~K}$ = five keys to entrepreneurial success in the 21st century: Key 1: Market definition, Key 2: Positioning, Key 3: Market perception, Key 4: Communication strategy and Key 5: Management capacity.

${ }^{14} 4 \times$ profit is called the Pyramid Paradigm (Close 2009) and refers to the 4 profits of values-driven entrepreneurship: profit for the customer, profit for society, profit for the environment and profit for the company, "profit" being a synonym for "added value".
} 
Fig. 2.6 Business transition

\begin{tabular}{cc}
\multicolumn{2}{c}{ Tusiness } \\
$\begin{array}{c}\text { Transformation } \\
\text { Traditional } \\
\text { entrepreneurship }\end{array}$ & $\begin{array}{c}\text { Multidimensional } \\
\text { entrepreneurship }\end{array}$ \\
Product oriented & Value oriented \\
Materialistic & Purpose driven \\
Competes on price & Competes on change \\
Hard & Hart \\
Money is goal & Money is a means \\
KPI Managed & Vision managed \\
Growth & Content \\
Personnel works & Personnel contributes \\
Optimization & Innovation \\
Individualistic & Cooperative \\
Short term & Long term \\
Follower & Leader \\
Distrust & Trust \\
$1 \times$ Profit & $4 \times$ Profit
\end{tabular}

Copyright: Jean-Paul Close

had crossed a line of saturation that made economies rise at the expense of stability. This also meant that business in general was taking values away in a destructive manner. A major crisis was only a matter of time.

While the need to balance social, ecological and value driven economies became a general coaching argument, a global movement appeared under the denominator "People, Planet, Profit." Both philosophies, the $4 \times$ profit Pyramid and the 5Ks compared to the PPP views, presented similar lines for progress, even though the international entrepreneurial description of profit was still predominantly referred to in terms of financial gain. My own definition of profit was expressed in terms of sustainable progress through the benefit of genuine human and ecological value creation. This distinction between money and value became very important. During 2008, a few analytical books on the $5 \mathrm{~K}$ multidimensional indexation of specific industries (supermarkets, banks and waste management) temporarily popularized the index, but also showed the dramatic state of the Dutch economy, society and lack of value-driven entrepreneurial spirit due to short term money-driven focus on survival. 5K Consultancy became more of an entrepreneurial service of painful criticism than support. The credit crisis in 2008 did not come as a surprise. In fact, it was welcome proof of insight that had been neglected for years by the Dutch and international financial institutions, business development and government. The subsequent massive capital injections into speculative banking, the Arab Spring as spinoff, the many different crises everywhere, the growing worldwide instability, and migrations as a result of natural and human-made catastrophes were a logical proof of the vision and awareness but also the persistence of global "leadership" to sustain the old paradigm at any expense. 


\subsubsection{Leadership Versus Management}

The 2009 book $^{15}$ in Dutch "Secrets of True Welfare" introduced the model of human and natural complexity that had been developed by deliberately trying to combine moral human complexity and ethical awareness development (TO BE) with the complexity of organizing human communities (TO DO), as explained earlier from a breakthrough point of view. The two lines were now plotted as two orthogonal lines in which both our organizations' structures evolve as well as our ethical understanding of ourselves.

A crisis is simply seen as the process of letting go of an obsolete past that gave a sense of security but reached a level of unsustainable progress. A crisis always brings in two psychological lines of action:

- Management: that tries to develop and maintain the past in an attempt to grow or optimize what was a cash cow or restore what threatens to be lost.

- Leadership: that accepts the breach and looks at ways to restore harmony by introducing adaptive innovation and change using new levels of awareness.

In The Netherlands, we could strongly sense bureaucratic management dominance at all levels of society. The past, based on welfare development, had been so rich, so wealthy and relatively safe that the entire democratic structure wanted to restore that kind of welfare and return to that past. Capital injections were applied and the bureaucracy enhanced to avoid change (the red line in the Fig. 2.7). Leadership (the green line) introduces changes that upset the structures of the past, which need to be replaced by modern interpretations of reality. But old structures have a lobby, an importance in the old infrastructure, and will pull other organizations along if chaos arises. A culture of avoidance and fear builds up, with tension between management and leadership. This starts with the dominance of management (the red arrow). Gradually, it becomes influenced by emerging leadership, either because the crisis is so strong that management cannot deal with it or because leadership's propositions get so much support that a change of sides must follow.

The credit crisis opened everyone's eyes (first awareness breakthrough) to the prospect that a total collapse could be expected and that this could be avoided temporarily and delayed only through artificial measures. Consultancy did not help anymore. To contribute to society, another vehicle was needed. In 2009, the STIR Foundation was launched. In my view, the cosmetic changes within an economy would not work anymore. We had to change things completely. Business development in the material world is in crisis due to misuse of our environmental and human resources. We needed to replace the central position of banks and money with something of much greater importance: the human being. If we exchange money-based welfare for human-based wellbeing, everything would change (Fig. 2.8).

\footnotetext{
${ }^{15}$ Close, J-P. (2009) Geheimen van echte welvaart.
} 


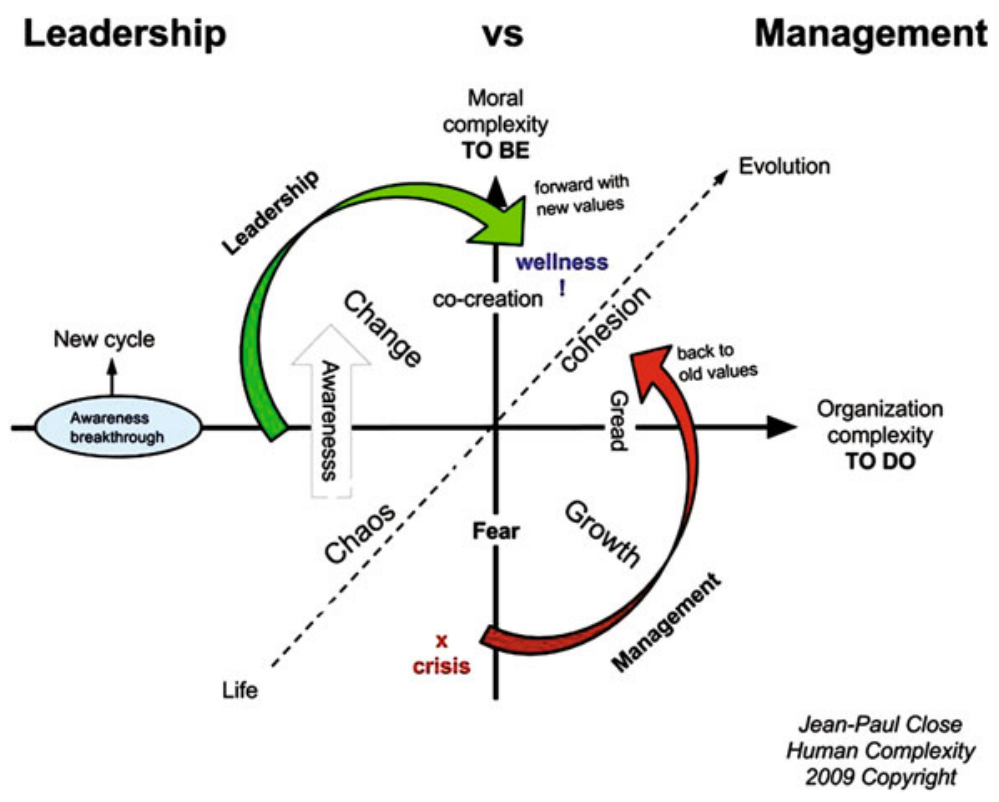

Fig. 2.7 Moral versus organizational complexity (color figure online)

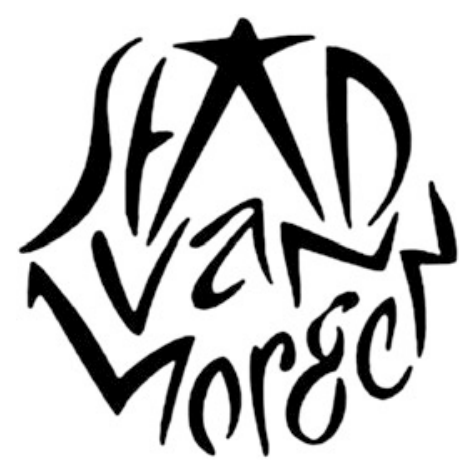

Fig. 2.8 The human being as central given in the City of Tomorrow (This first national logo shows an artistic approach, placing the human being centrally in the text "Stad van Morgen" (City of Tomorrow) - this logo was a contribution to STIR by De Heeren van Vonder in Eindhoven)

\subsubsection{STIR Foundation-City of Tomorrow}

The foundation had the objective of positioning itself in the field of awareness-based co-creation towards key human values of wellbeing, a drive for transformative change that affects the entire society. Wellbeing, in terms of 


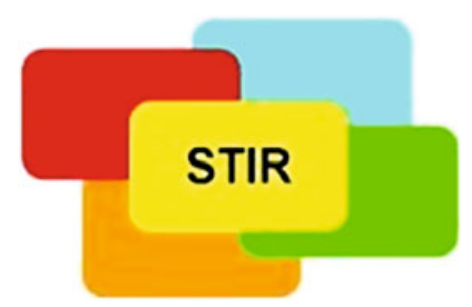

Fig. 2.9 The international STIR logo (The international logo of STIR shows the awakening STIR consciousness in the center, surrounded by balancing spiritual, emotional, physical and rational awareness) with consciousness as learning vehicle

harmonizing society around the evolutionary aspect of "sustainable human progress", was defined as (Fig. 2.9):

Sustainable human progress is to keep working together on a healthy, vital, safe, self-aware and self-sufficient human society within the context of our ever changing natural surroundings. ${ }^{16}$

This definition served the STIR mission better than the 1987 Brundtland $^{17}$ definition put forward by the United Nations:

Sustainable development is development that meets the needs of the present without compromising the ability of future generations to meet their own needs.

STIR could take personal and institutional responsibility for wellbeing-based harmonization of our present time, as well as our responsibility for the wellbeing of future generations. Having defined our common sustainable evolutionary focus, a new phase in our democracy could be announced. We had no more need to debate our direction, because that had been fixed by the sustainable human progress and wellbeing definition. We could engage by synchronizing our decisions and priorities to this definition rather than spending time democratically disputing the direction from self-interested points of view, often prioritized by our dependence on money rather than our ability to create true measurable values.

\subsubsection{Sustainocracy}

A new model with which to calibrate our societal structure was born. It distinguished itself in name, commitment, energy and mission from the old democracy. For a long time, liberty, as in the sense of 'democracy,' the participative ability to vote for decision-makers, connected the powerfully desired freedom of speech and

\footnotetext{
${ }^{16}$ Geheimen van echte welvaart-Close (2009).

${ }^{17}$ Redclift, Michael. "Sustainable development (1987-2005): an oxymoron comes of age." Sustainable development 13.4 (2005): 212-227.
} 


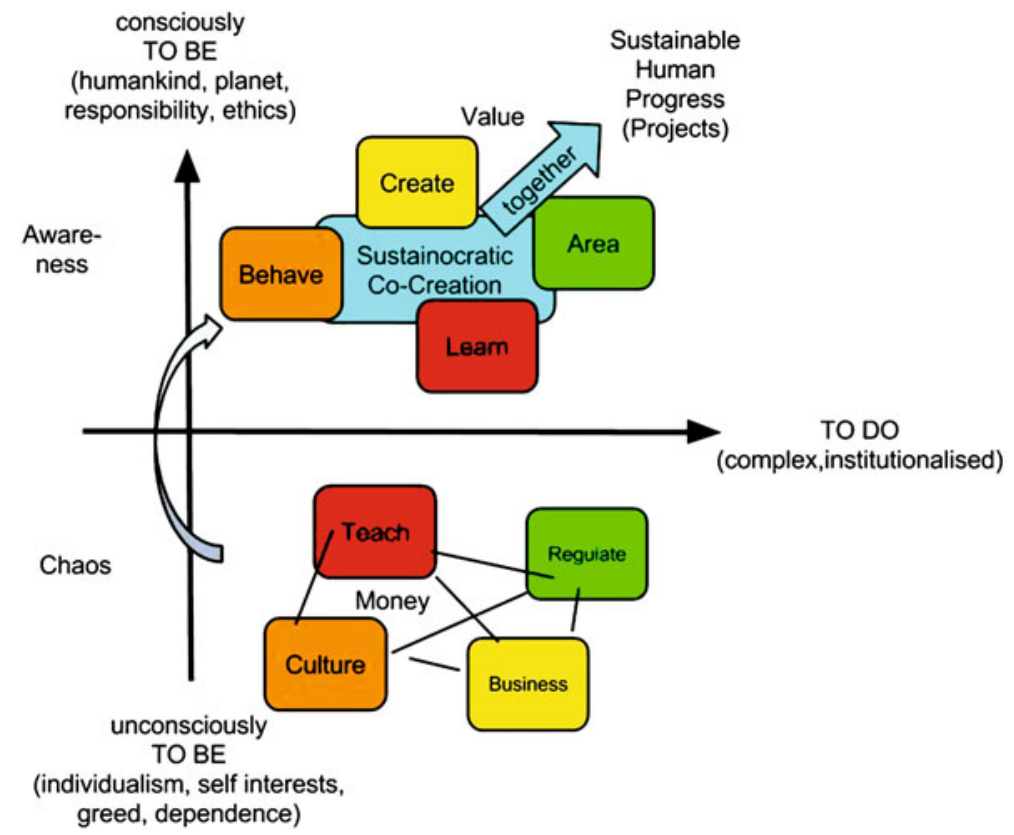

Fig. 2.10 The transition to co-creation based on awareness

choice in times that this was not common practice. Now that we have this sense of liberty, we find that communities tend to value personal securities as a common right and develop hierarchies of greed using democratic processes that do not include productive patterns to sustain those rights. The current democracy became firmly anchored in the engagement with the money-driven welfare structure and individual desires for financial growth as a perceived form of social security.

When it became clear that this democratic structure had destructive consequences, apparent during the current period referred to as the Anthropocene, ${ }^{18}$ there was no way to deny honestly that an alternative was required. We needed to reflect on our actions and redefine who we are as a species. With 7 billion living participants in our species we could not afford to learn through our mistakes anymore. Sustainocracy invites us to engage in sustainable human progress by defining and accepting concrete human values, key responsibilities and ethics that have appeared in our mind while suffering the consequences of our old behavioral patterns and governance (see Fig. 2.10).

The term Sustainocrat was introduced to represent sustainable human progress with which to connect. It is physically represented and symbolized by a real (independent and free) human being, a symbolic function that engages all possible instruments in the sustainable progress definition. This human being symbolizes the

\footnotetext{
${ }^{18}$ The term "Anthropocene" was introduced by Alexei Pavlov in 1922.
} 
value-driven evolutionary essence of the species, replacing the money-driven image of a bank in the old system. With the contrast between two different paradigms now defined, visualized and personalized through positioning of the Sustainocrat, the mission could be unfolded into a new societal complexity.

\subsubsection{City of Tomorrow}

The STIR Foundation's mission rapidly received a new name from its early participants in 2009. They started referring to the activities as the "City of Tomorrow". STIR found an initial positive entrepreneurial setting in the new International Center of Sustainable Excellence (ICSE) in Eindhoven. This ideological center was positioned to help develop awareness through conferences and a permanent exposition of enterprises that had a story to tell or a product to show in the context of some explanation of sustainability. City of Tomorrow initially seemed to fit well among other inspiring initiatives, such as The Natural Step, ${ }^{19}$ Cradle to Cradle, ${ }^{20}$ Biomimicry, ${ }^{21}$ Earth Charter, ${ }^{22}$ etc. Surrounded and interacting with dozens of value-driven initiatives in the field of "sustainability," 23 STIR organized congresses and a large variety of purpose-driven working groups. Issues like energy transition, $\mathrm{CO}_{2}$ emissions, healthcare costs and transformation, sustainable housing, city quarter transformation, mobility, the new way of working, leadership, healthy schools, education, pollution, etc., were addressed. However, the obstacle of the money-driven mentality of participants, and a transaction-based economic reality, reversed responsibilities. As soon as an initiative was close enough to start up as a pioneer, the arguments about ownership, business concept and profit allocation would break up the alliance. Self-interest still prevailed for the sake of individual survival in a society that had been hijacked by banks through long term public and private $^{24}$ mortgages and debt structures. Most people had important financial obligations to deal with every month and forcefully ran a short term survival scenario without time, room or support to fulfil a more complex leadership vision and mission. Only people that could break free from such burdens could connect to the leadership initiatives of Sustainocracy.

\footnotetext{
${ }^{19}$ Robèrt, Karl-Henrik, and Ray Anderson. The Natural Step story: Seeding a quiet revolution. Gabriola Island: New Society Publishers, 2002.

${ }^{20}$ McDonough, William, and Michael Braungart. Cradle to cradle: Remaking the way we make things. MacMillan, 2010.

${ }^{21}$ Benyus, Janine M. Biomimicry. New York: William Morrow, 1997.

${ }^{22}$ Earth, Our Home. "The earth charter.” Worldviews 8.1 (2004): 141-149.

${ }^{23}$ No single definition for sustainability existed. Every organization and individual defined it in their own way. The most common interpretations were around energy (e.g., solar panels) and material resources (e.g., Cradle to Cradle). Not many people referred to the vulnerability of the human being, but mostly to the risks to our well-being and luxuries.

${ }^{24}$ Debelle, Guy. "Macroeconomic implications of rising household debt." (2004).
} 
The business case of ICSE suffered, and the organisation went broke within one year of its announcement; however, it left a lasting impression in the City of Tomorrow. The short period of the ICSE was significant for three reasons:

1. It brought people into contact with a large spectrum of other value-seeking people who were willing to invest time and effort in experimenting with co-creation. This is where people like Nicolette Meeder and Marco van Lochem engaged with the ideology of transformative change represented by the City of Tomorrow and Sustainocracy.

2. It connected value driven initiatives with local city government officials who were often much more developed in awareness and drive for sustainable progress than their counterparts in business sectors. This could be explained by the fact that government relied on tax income, not on banks. Their type of engagement to money and society was different than self-employed individuals who often had the burden of a mortgage, monthly rent and the cost of college-going children.

3. If we wanted to survive, with an aggressive world of transaction and debt-based finance as a point of reference, we needed to develop exactly the opposite (from welfare to wellbeing).

Large business enterprises had both the burden of debt and financial pressure from shareholders. The fragment perception of each societal participant in a money-driven world was based on self-preservation and survival, as shown in this picture (Fig. 2.11).

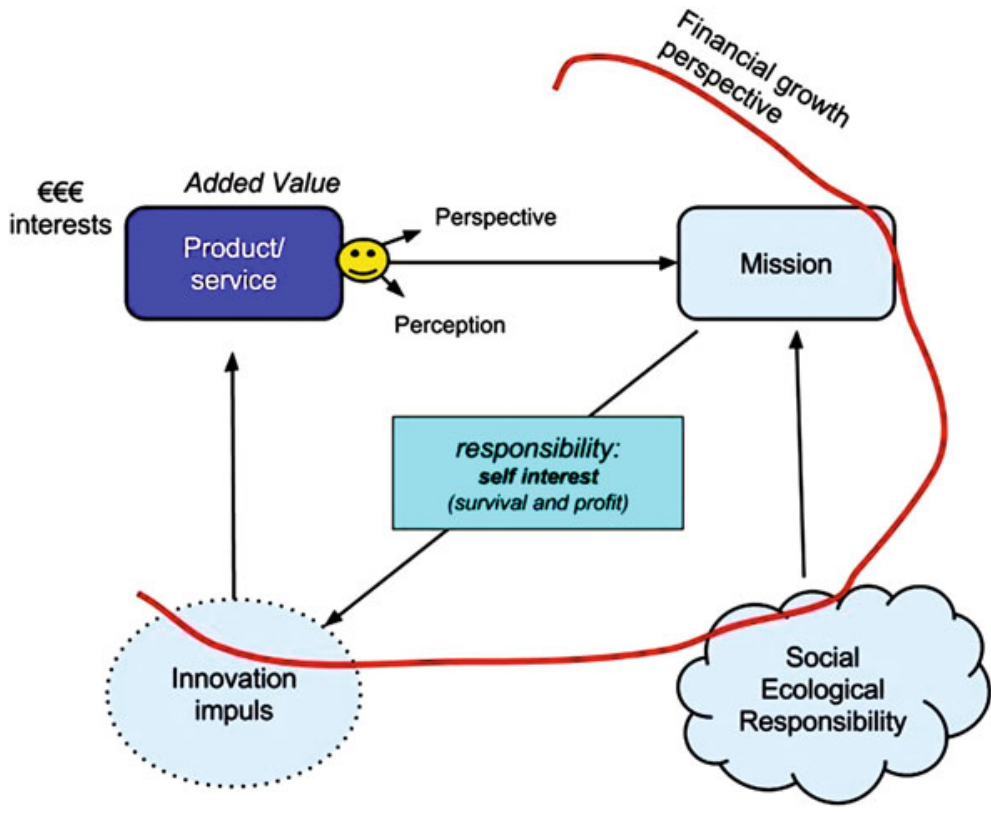

Fig. 2.11 The tunnel vision of fragmented self-interests 
City of Tomorrow should not position itself as a new product or service in welfare development, but within the complexity of the holistic wellbeing mission. All the work done in the STIR Foundation had resulted in enormous insights around the transformative complexity that we were facing, but it had not resulted in a definite multidisciplinary commitment or breakthrough. Over 20,000 full-time professional freelance hours had been invested in the learning process. The lack of concrete progression was blamed on the fact that the transitions were nearly always focused on transforming a field of interest that was in the hands of powerful economic and political drivers. Transformative initiatives were always envisaged from within the money-driven culture of economic growth, through product innovation and change of players rather than change of culture. The tension between new ideas and the old establishment was nearly always won by the establishment. In February 2010, it was decided that all the City of Tomorrow workgroups would be dissolved and the ICSE abandoned.

It had become clear that one cannot teach or support others to take on the role of Sustainocrat, because we live in a product- and services-driven culture and structure. If I wanted wellbeing, I had to take responsibility myself, both ideologically and practically. In 2010, the new city council of Eindhoven was addressed in a speech about Quality of Life, in which the desire was expressed to co-create a self-sufficient, healthy, energy-neutral city by involving the citizens, government and business innovators. The council reacted positively and asked the representative councilor to discuss the matter with the City of Tomorrow. He waved the suggestion away with the wish to see if the city management could take benefit of the movement by establishing a potential energy and quality of life cooperation itself. There was, again, an obvious economic component to his suggestion, in an attempt to solve the crisis in the city finances.

This political contact and evasive response did not discourage; it just confirmed that fragmented trade issues, such as energy, mobility, housing, education, care, etc., with a powerful economic component and structures of power, would be extremely difficult to tackle using ethics and common sense alone. They would probably need a crisis of their own, a collapse or at least a strong threat before real change would be introduced or accepted. Meanwhile, the battle for ownership and control would continue. In view of STIR, this would further destabilize the community while fragmented self-interests competed for the leftovers of economic drivers in an attempt to sustain themselves at the expense of others. A shakeout was taking place, and everyone was trying to save their institutional souls. Only chaos would lead to openings (Fig. 2.12).

\subsubsection{The Amsterdam Internet Congress}

The above difficulties in breaking through the status quo of an obsolete but itself sustaining (against all odds) societal structure had become a challenge for STIR. The sum of the competing fragmented interests and reluctance or imposition of each 


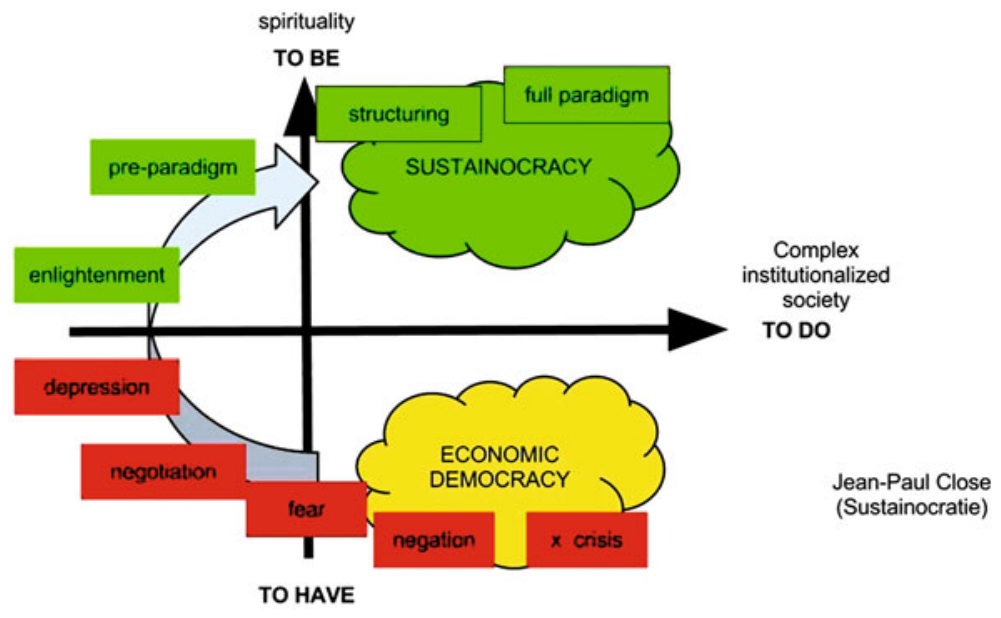

huge spiritual educational process

Fig. 2.12 In 2009 and 2010, negation and fear of collapse was still dominant

fragmented structure to take responsibility for the transformative needs was the theme of a speech during an internet encounter in Amsterdam. Several pioneering organizations from cities around the world participated through video/conference. City of Tomorrow was one of three speakers:

- City of Tomorrow: The difficulties in getting fragmented money-dependent structures, including government, to engage in proactive human value-driven responsibilities;

- Cisco: Explaining the experiences of the "new way of working" (a type of technology-facilitating home working scenario) in relation to the reduction of $\mathrm{CO}_{2}$ emissions.

- University of Madrid: Showing a 3D presentation of air pollution over the city of Madrid.

Both projects were ending due to lack of funding or the end of a trial period. This experience resulted in the City of Tomorrow combining the above insights with its own STIR initiatives and experiences. Taking air quality, human health and regional dynamics together in a conceptual approach became a source for innovative inspiration for the first time. Cisco did not respond to the invitation to seek continuity of their project in Eindhoven, but the University of Madrid representative did (Photo 2.1).

Owing to the lack of response from Cisco, the STIR Foundation's City of Tomorrow lacked direct access to technology and ICT development structures that could take over the commitment. Within the circle of relationships that had been built up in the City of Tomorrow, Marco van Lochem had signed up. 


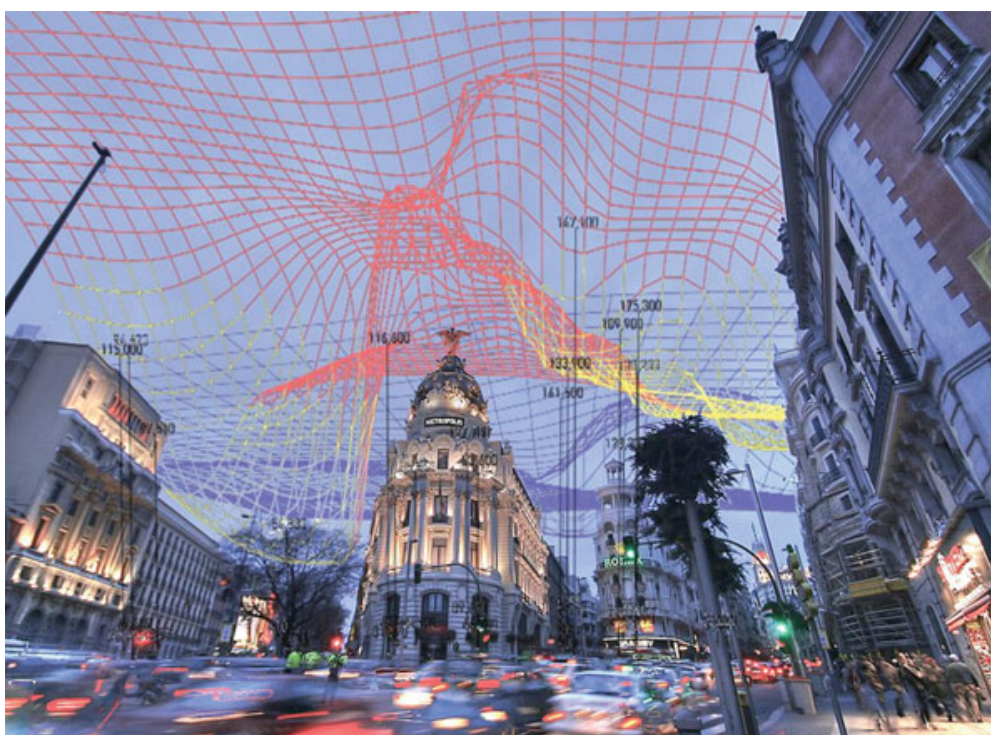

Photo 2.1 The inspiring image produced by the University of Madrid

- Marco van Lochem presented himself as a new age entrepreneur with an extensive CV and relation network in the high tech business world, becoming a sponsor and member of the STIR Foundation. When he heard the suggestion to create a "healthy city" initiative from social and technological perspectives, he decided to commit, and AiREAS was born.

\subsubsection{Key Elements that Define "Sustainocratic" AiREAS}

AiREAS became the first structure defined primarily from human (not system) ethics and a point of view of responsibility (healthy city mission), with the structure defined subsequently (multidisciplinary co-creation). "To Be" would lead and "To Do" would follow. This turnaround was extremely significant, not just in its positioning as an awareness breakthrough organization but also in its way of working. The key elements were:

- Purpose driven (healthy city)

- Wellbeing not welfare

- No hierarchy (health and air quality dominant, not politics or economics)

- Shared responsibility

- Change driven

- Money not the primary consideration 


\section{A(p)REAS}

Fig. 2.13 The AiREAS logo as designed by Marco

This is very meaningful, because it does not simply refer to a business case, it represents a first delicate step into a new type of society defined around a deeper awareness. It would show that evolution is not just limited to individuals but also to the way we interact and create innovative types of communities.

\subsubsection{AiREAS}

The first working name in the City of Tomorrow was ID City Home, referring to the holistic ideology of sustainable progress at the city level. It was the workgroup name in the City of Tomorrow for city development. The name needed to be changed into something that could be related to Air Quality and Regional development. It was Marco who came up with the idea to combine AIR with AREAS. He suggested the "AiREAS" name. The representation of the "i" as a sensor completed the picture, which was also designed by Marco (see Fig. 2.13). The co-creation was operational even if it was only at the level of two individuals.

Meanwhile the AiREAS multidisciplinary venture was being presented to all kinds of potential partners. City officials of Eindhoven had informed us that AiREAS was not necessary because the city was already taking many measures through the Dutch Air Quality Platform that provided funds for infrastructural changes, such as tunnels, traffic light systems, etc. These funds were channeled through the Province of North Brabant. If AiREAS wanted to do something in this field, it would need to address the Province first. This brought AiREAS in touch with two key influencers in the process:

- Eric van Merrienboer, former member of the city council of Eindhoven and now director of mobility and economy in the province. Eric influenced the positioning of AiREAS by suggesting the involvement of the four key societal players around the issue: government, science, citizens and business innovators. He was also responsible for the internal distribution within the province of the initial City of Tomorrow proposition to set up AiREAS (Fig. 2.14).

- Edwin Weijtmans, air quality program manager in the province. Edwin received the proposition and was very enthusiastic about it. He invited AiREAS (still consisting only of van Lochem and Close) to visit the province, and an alliance grew. Edwin provided the very first small funding $(€ 25,000)$ for the City of Tomorrow to develop the AiREAS Proof of Concept (Fig. 2.15). 


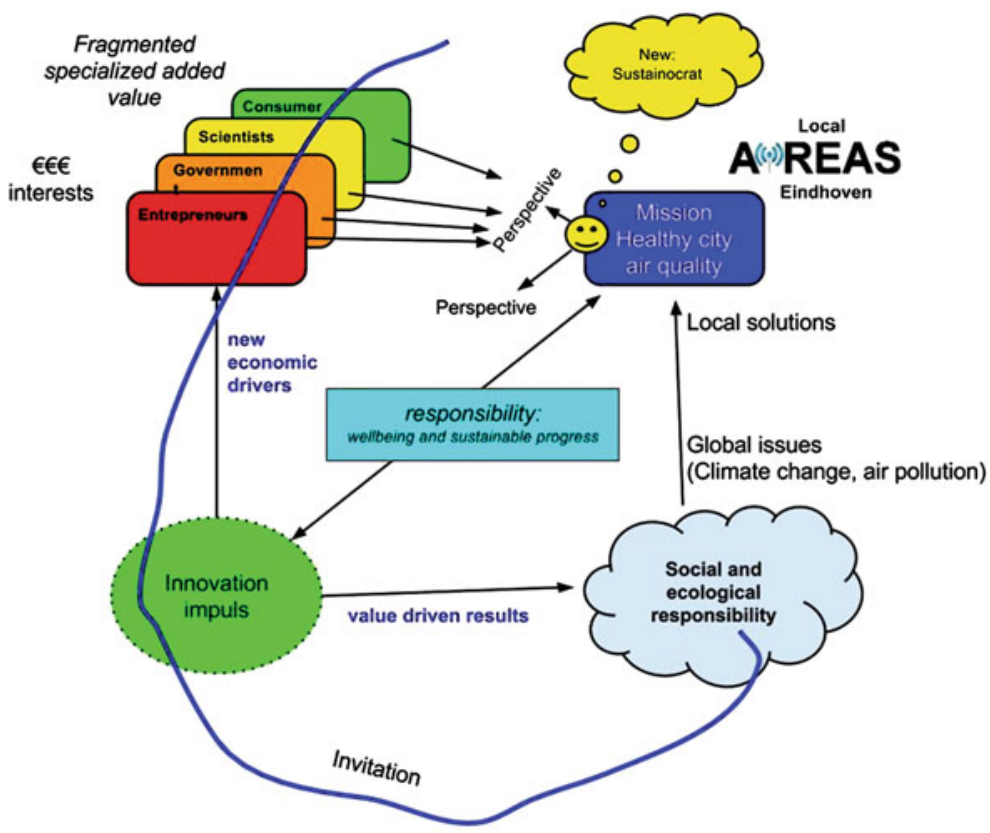

Fig. 2.14 The change of perspective of a Sustainocrat, positioning him/herself in the field of a collective value-driven mission

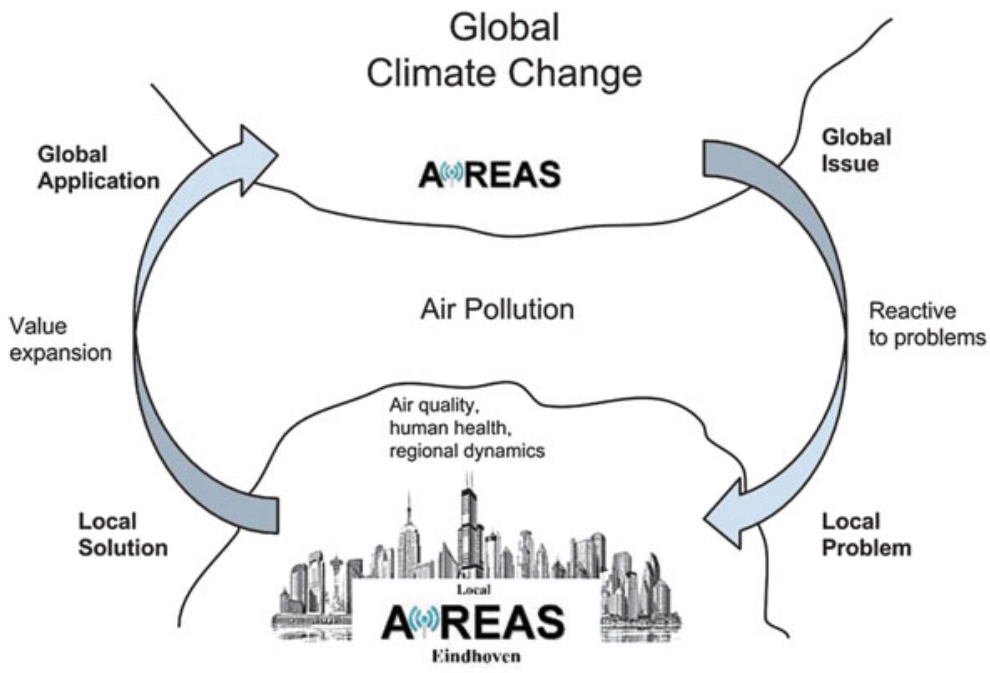

Proactive economy based on value creation

Fig. 2.15 The Local AiREAS mission for human health is inspired by the global issue of environmental pollution and climate change 


\subsubsection{Commitment First}

With the commitment of the province to AiREAS, and the Sustainocratic format to be filled in with multidisciplinary partners, the search continued to develop a consortium. The City of Tomorrow had developed the following value-driven formula to be applied and to distinguish ourselves from the money-driven relationships. Reciprocity is a word that provides a better sense of the return on investment, inhabiting, as it does, a much broader scope than mere financial profit. In the world of trade and financial profits, people engage for just that. In AiREAS, one would engage primarily for "health and environmental quality". AiREAS would be organized in a result-driven, not demand-driven, way, as the mission for a healthy city had been formulated into the very purpose of AiREAS.

Talent $\times$ Input $\times$ Sustainable Human Progress $($ Purpose $)=$ Innovative steps

(Result) $\times$ Reciprocity (Return)

In January 2011, the first true AiREAS multidisciplinary meeting was organized at the Airport of Eindhoven, with the participation of the Intheair.es 3D initiative from the University of Madrid, ITC University of Twente, Philips Lighting, TomTom, Edwin Weijtmans (province of Noord Brabant) and a representative of the City of Eindhoven, together with the two founders. The purpose of the meeting was to cement multidisciplinary support and commitment from the participants for the suggested venture (Fig. 2.16).

All participants but one committed (the one deferring because of internal struggles in the company to define their own purpose for the future). The formal cooperative was then registered. Dutch laws do not yet accommodate the registration of value-driven cooperatives, just money-driven ones. This was the first obstacle, an ideological challenge to the current legislation in Holland which supports just one paradigm (welfare). It was temporarily overcome by incorporating

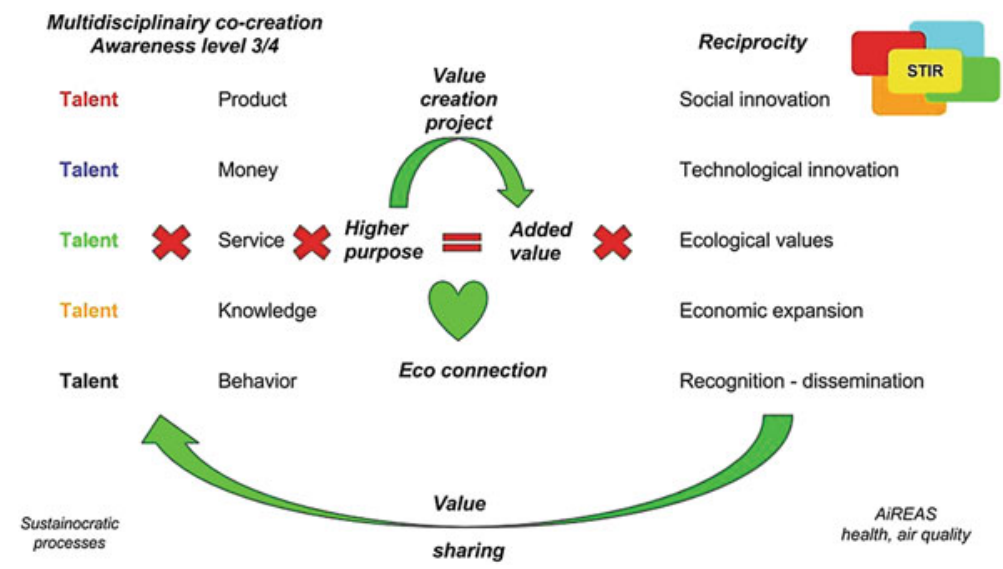

Fig. 2.16 the multidisciplinary sum of talents 
constitutional identifiers that allowed us to modify the purpose of the cooperative using our first membership encounter. More obstacles would soon be encountered, demonstrating that transformative change is not just related to practical issues of innovation but also introduces profound discussions on the constitutional and legal formalities that block disruptive processes, standing in the way of sustainable progress. AiREAS was transforming into an initiative that was making the invisible air pollution much more visible.

In June 2011, AiREAS presented its Proof of Concept on a national level in the province of North Brabant. Despite the ideological support of all participants, the invitation to take mutual responsibility was not seconded. The nationwide approach was too far-fetched and the fragmented positions of potential partners too individualized. In some cases, the institutional justification of a potential partner was related to the problem, meaning that elimination of the problem would also eliminate the institution. Institutional self-preservation thus also demanded preservation of the issue, no matter how debatable morally, positioning the organization at the consequence-driven reaction side within the related secondary economy. Comments heard were:

- We don't address over-consumption, we deal with overweight.

- We don't support self-sufficiency because it cannot be taxed.

- We don't deal with healthy air, we repair broken lungs.

This showed yet another complex issue of the dual welfare economy that we had created, the one of economic growth against all ethical awareness, and the economy of speculative care trying to address consequences through remedial tax and insurances. Those in the economic field of growth have an ethical issue to deal with, while those in the economic field of caretaking define their existence in regard to the problem through remedies. Both have a problem with participation in City of Tomorrow transformative processes such as AiREAS because it challenges their own long term existence. Only when the potential partners are aware of the chaos they inflict, or contribute to by their mere existence and management attitude, do they become willing to address their own identity and position themselves experimentally in true value creation. They benefit from it by challenging their own reason to be through the redefinition of their own purpose and contribution to humankind. In this process, many find an unprecedented potential that justifies participation in AiREAS. During the process, it became clear that specialized civil servants were often more advanced in their own entrepreneurship and leadership for regional harmony than business people or scientists. The differentiators in financial and societal engagement of each potential participant became clear, as did the way each perceived the world from their own position. Bridging this perception to the collective, multidisciplinary "healthy city" mission in AiREAS became an awareness trigger for most participants and something they were able to come to terms with personally as well as institutionally. Self-inflicted obstacles, proper to the old paradigm, showed up in the development of the AiREAS commitment, allowing the self-aware institutional executives to redefine their inner structures accordingly. 


\subsubsection{Territorial Focus}

We came to the conclusion as a group that we needed a smaller territory that could act as living lab. This territory should be complex enough to justify a multidisciplinary coalition and co-creative enterprise, yet small enough to produce a single top-down commitment to making it happen by taking responsibility within the connecting process. New city council elections in 2010 had created a new directive in the city of Eindhoven in which applied innovation, civilian participation and sustainability were spear points. The newly installed but experienced city councilor, Mary-Ann Schreurs, proved visionary and possessed of a great willingness to participate. "Yes, we want this," was the simple but significant email response that returned the AiREAS effort to Eindhoven. The first Local AiREAS Eindhoven was started as a living lab for applied innovation, citizen involvement and research.

\subsubsection{Local AiREAS Eindhoven}

In September 2011, the first Local AiREAS Eindhoven meeting was held. I presided over the encounter as a local entrepreneurial civilian representing wellbeing-based sustainable human progress. I had become the first "Sustainocrat." "The world upside down," said the environmental program manager, civil servant Hans Verhoeven, who had been selected by councilor Schreurs to represent the local government and its infrastructure. He said this in response to meeting this civilian, who had invited local governance to take responsibility with him "to co-create a healthy city," rather than the other way around. This statement, "the world upside down," became a characterization of the transformative processes in which we had all gotten ourselves involved (Fig. 2.17).

The first multidisciplinary "healthy city with air quality" encounter started with an empty table, no budget, all kinds of possible talented partners, and the higher purpose of a healthy city with air quality and human health as its value-driven purpose. Representatives of government, business, science and civilian groups were assembled around the table. The first priorities and action points were to be established in an open democratic dialogue. The setting was based on equality

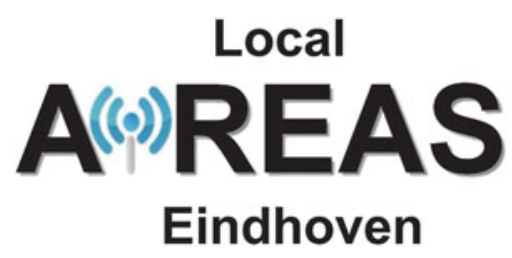

Fig. 2.17 AiREAS represents the ideology and co-creative format, Local AiREAS (city) the regional execution 


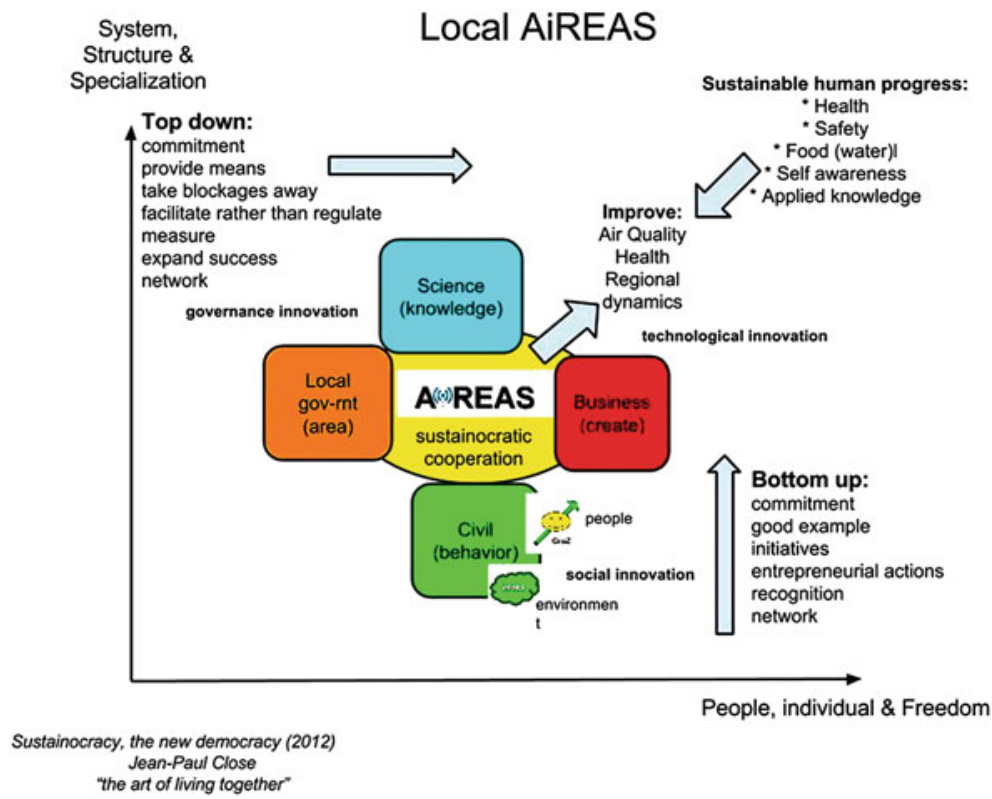

Fig. 2.18 The AiREAS "healthy city" commitment

among all participants. The higher wellbeing purpose of "healthy city through air quality" was what would lead us, not welfare-based politics or economics. No one was "the boss." Each present carried their own responsibility, talent and authority, with the invitation to use it well by creating value together (Fig. 2.18).

\subsubsection{First Things First}

Councilor Schreurs argued that the city had no own insight into its own air pollution patterns. It depended entirely on the reports that were presented by national organizations such as the Ministry of Health (RIVM). There was no possibility of addressing the issue locally, because the problem was invisible for the local people and policymakers, while interpretation of responsibilities was done outside the scope of the city. The first priority would be to gain insight of our own at the city level. The objective was to gain knowledge about local air pollution in relation to human health. This would trigger value-driven innovation and support important decisions that the city council had to make for the coming decades. We therefore needed to look into the possibility of measuring pollution as closely as possible within the outdoor space of the local population. A first multidisciplinary challenge and priority was born. It became step 1 and phase 1 of Local AiREAS Eindhoven. 


\subsubsection{Making Visible the Invisible}

The project "making visible the invisible" started to take life among the participants, linking the potential of technological and social innovation with ideals of creating a healthy environment and the need to reflect on city dynamics using real, locally-validated data rather than those handed down from external authorities. The need to measure as closely to the population as possible introduced issues like modelling techniques, presentation and interpretation of data, density of the network so as to be able to arrive at conclusions or cross-referencing and analysis of data from different sources (e.g., medical statistics with air pollution history), privacy of the population, etc. The scientific partners of different disciplines were taking responsibility for the application of existing knowledge and the research potential of the network and mission envisaged. This is described in the Chap. 3 of this publication. From a technological point of view, choices needed to be made around available technologies in the market and the purpose that we wanted our network to serve. These choices are also described in detail in the next chapter of the book. At this stage, the measurement network was handed down the following requirements:

- Real time measurements;

- Measure a large spectrum of pollution, including $\mathrm{NO}_{2}$ and the Ultrafine Particle innovation presented by Philips;

- Measure at postal code level (the closest to the human population without invading privacy);

- Low maintenance costs and risks (validation, reliability, availability, etc.);

- High quality, calibrated information gathering;

- Low cost (referenced against the expensive official measurement stations used by the central government).

A partner consortium, consisting of ECN, Imtech (later Axians) and Philips, decided to take on the technological challenge with the following distribution of tasks:

- ECN: equipment design and assembly-Rene Otjes;

- Philips: Ultrafine particles-Ronald Wolff;

- Imtech: data communication and storage-Carl Wolf.

The team was completed with:

- Scientific insight lung and respiration: IRAS (University of Utrecht)—Dr. Gerard Hoek;

- Scientific insight modelling techniques: ITC (University of Twente)—Prof. Alfred Stein and Dr. Nicholas Hamm;

- City infrastructure and services: Officials of the City of Eindhoven-Hans Verhoeven and Sandra van der Sterren. 
The project had highly technological characteristics. It was therefore to be led by co-founder Marco van Lochem as an independent and connecting Sustainocrat. The entire team was given the internal name "ILM" (Innovative Lucht Meetsysteem $=$ Innovative Air Quality Measurement System). Sustainocrat Jean-Paul Close would concentrate on the bigger picture and involvement of the complex "soft side" of AiREAS, the civilian participation, while looking for new steps to take.

\subsubsection{From Idea to Project}

With the abstract mission of a "healthy city" now focused on its first concrete step, the ideological to practical development could be discussed and budgeted. All partners would invest in this first step. Financial means were committed by the two participating governments, the City of Eindhoven and the Province of North Brabant, and the technological partners. The project details were summed up by Marco van Lochem through milestones (Fig. 2.19).

Between September 2011 and January 2012, various meetings resulted in all parties agreeing on the technical aspects of the ILM, its assumptions and expectations, as described in Chap. 3. Despite the financial commitment of the two representatives of government, the project still needed to be passed and approved by all the bureaucratic layers of the city.

\section{A(s)REAS Planning \& Doorlooptijd}

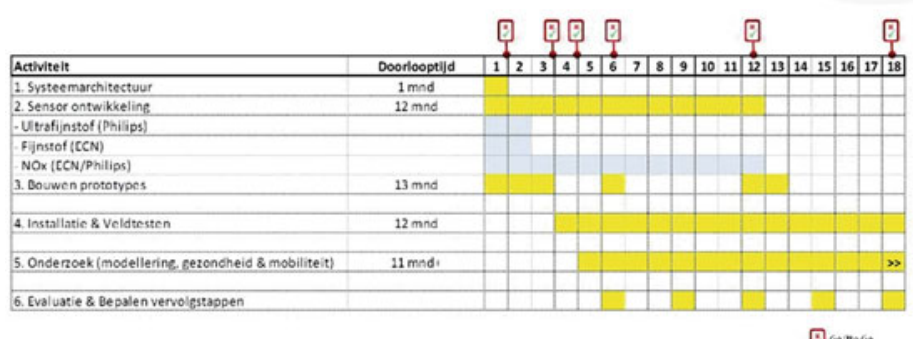

g...

- AIREAS Cooperative Association

Fig. 2.19 The original planning of the ILM in January 2012 
The city of Eindhoven had been affected by the credit crisis and needed to reduce its costs and investment schedules for the coming years. Any new project or financial commitment would require poaching from other plans, commitments or running budgets. All these budgets had already been scrutinized due to the financial savings required. The city was also in the process of drastically reducing its human resources, so little sympathy would be encountered when new projects needed to be accommodated at the expense of others.

The AiREAS community was ready but the participating civil servants now needed time and determination to get the commitment materialized within their own institutions. A global kick-off was announced for June 2012. As this date approached, it became clear that the funding had not yet been cleared by the system. AiREAS decided to go ahead with the meeting, simply to maintain the cohesion of the group and reassure the commitment by all in the process. A new date for the global kick off was set for October 2012. This time, the funds were cleared and phase 1 could start. The October 2012 kick-off became an emotional relief for all involved, a milestone and welcome proof that a complex group could engage in a complex holistic, human value-driven setting. The new paradigm was now a practical reality, and we were going to make it happen. The AiREAS group had taken multidisciplinary responsibility and now had the task of making its commitment come true (Photo 2.2).

Photo 2.2 Marco van Lochem presiding at the October 2012 kickoff

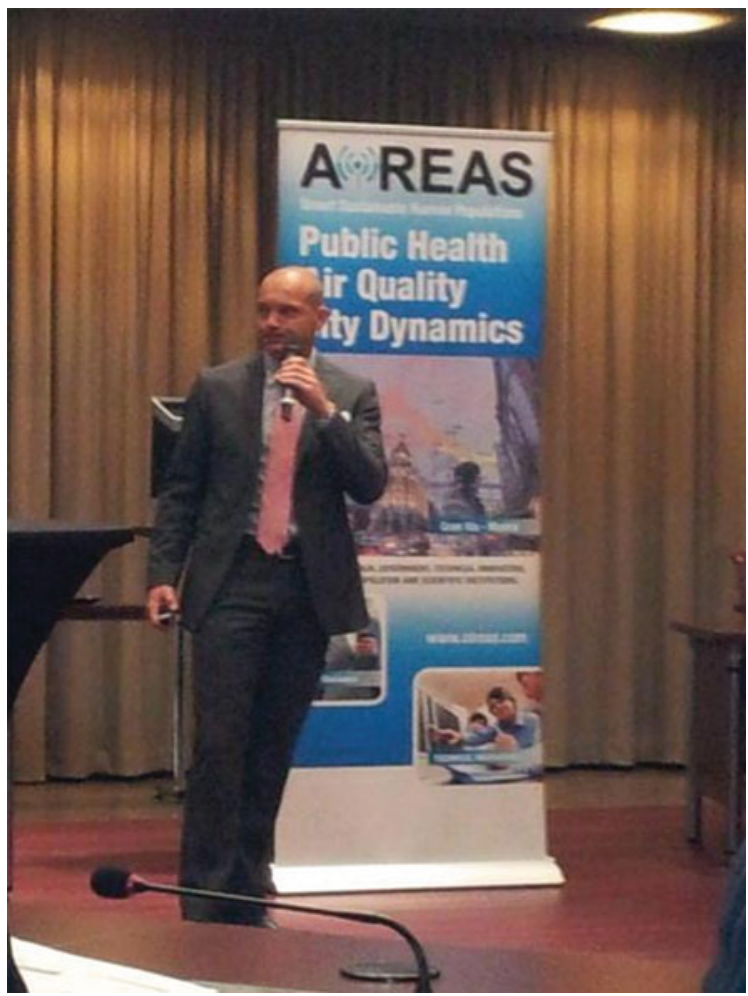




\subsubsection{Conclusion About the Coming About of AiREAS}

The above story shows how difficult it is to thoroughly engage all components of a complex society in a totally new directive. We can summarize the following aspects as being key to the process:

- Someone, independent of the reigning system, needs to define the common mission and take the initiative of inviting co-creation;

- Depression and (expected) chaos is needed to open the door for propositions of change through awareness and need;

- The right people, with the right need, awareness or mentality and authority, will engage when the proposition suits their interest;

- Key to the territorial partnership is the commitment of local governance;

- The proposition should be complex enough to be challenging beyond the power of influence of the fragmented authority, and small enough to be achievable in a defined time interval;

- At one stage, the initiative should be depersonalized and become a group process with group results;

Recognizing this complex, time-consuming process, it can be repeated as often as global issues demand local solutions. In AiREAS, we have come far, starting with the personal awareness, commitment and determination of a single individual who, after many trials and errors, manages to find and connect people and institutions to make a group commitment. This commitment received the name AiREAS and developed into numerous new age expressions, such as Sustainocracy, multidisciplinary co-creation, the Sustainocrat, value- and result-driven wellbeing-based cooperation, the transformation economy, etc. Without the credit crisis, the doors would probably never have opened to address the issues that we face.

\subsubsection{Link with Ethics and Economies}

In September 2012, an intellectual gathering in Visegrad, Hungary, with the participation of over 30 countries, discussed the practical evolution of ethics and economies. The presentation and paper about AiREAS in Eindhoven as an evolutionary movement for business and society was accepted and published. ${ }^{25}$ It proves the pioneership that AiREAS as a group is introducing for a new interpretation of our reality. The powerful alliance in Eindhoven has proven itself to be a warm, heart-driven commitment that unites seemingly contradictory interests in a common, purpose-driven mission in which the contradictions become complementary forces. The same model can be applied for any issue that humankind faces

\footnotetext{
25“"The spiritual dimension of business ethics and sustainable management", Corvenius University Budapest 2014-Springer.
} 
in the complexity of sustaining itself as a productive species within the dynamics of an evolutionary natural environment, balancing welfare and wellbeing with wellbeing as the dominant resonance for behavior and structure. Within the current human hierarchies developing capitalism- and consumption-based economics, "ethics" is often defined in legal terms to sustain the political and economic system through lawful public solidarity. In Sustainocracy, however, we place ethics at the level of understanding life and its complex harmony with its surroundings. We develop moral wellbeing around the key values that we have defined for stable communities (To BE). Ethics hence becomes a universal truth of life, not a political or economic one. Having said that, and differentiating now between the transaction-based economy of capitalism and the value driven co-creation of Sustainocratic processes, we can link these systems as well in a coherent self-regulating circular economy (Fig. 2.20).

When we position the fragmented reality of our current institutions, we can conclude that, in our current reality, all operational elements interact within the area of economic growth (the left hand side of the cycle). The necessary self-regulation on the right hand side has not been activated consciously and is left over by the cyclic intervention of nature itself. We become aware through crisis and chaos on the growth side, only then allowing value-driven innovation to initiate a new cycle. By permanently activating the value-driven side, calibrating growth against the harmony of sustainocratic values, a self-regulating mechanism is also introduced into the nature of economics. Without the need to wait for collapse, it challenges growth with continuous change, which is also the way nature works, introducing innovations continuously to sustain life rather than destroying it.

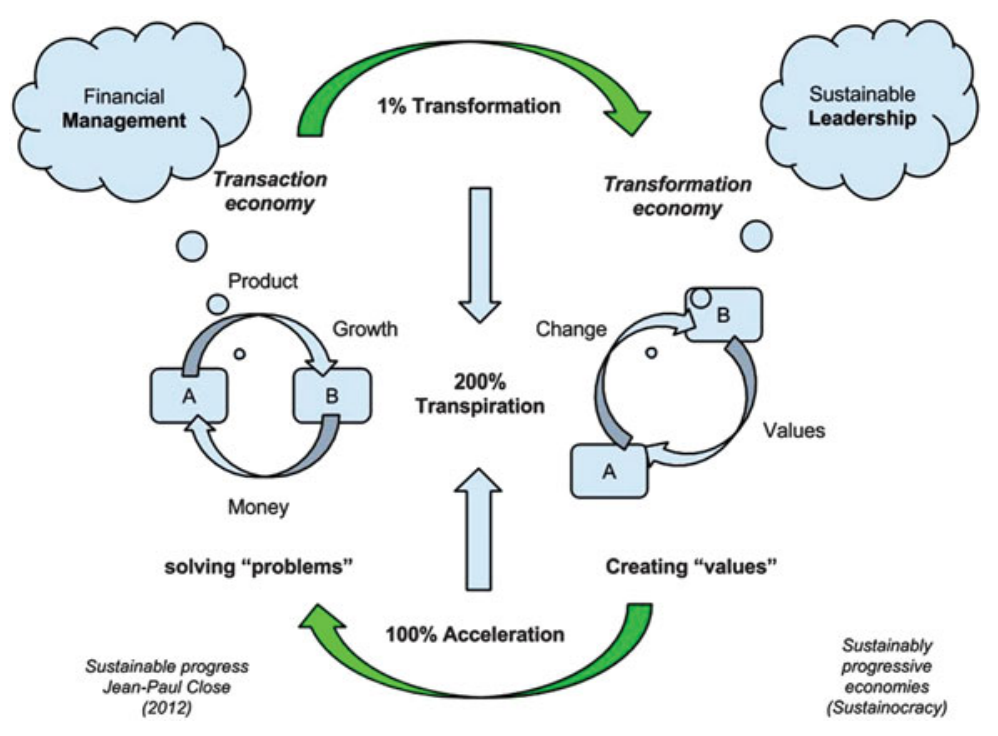

Fig. 2.20 Introducing the transformation economy 
This analysis shows how AiREAS is positioned on the side of the transformation economy, resolving harmonization issues with our local health and air quality, while feeding the economy of growth with a whole series of value-driven innovations and proof of new concepts. Ideally, society is permanently positioned on the side of value-driven change while business develops the economy of growth. AiREAS is proof of the principle in this line of thinking.

Open Access This chapter is distributed under the terms of the Creative Commons Attribution-NonCommercial 4.0 International License (http://creativecommons.org/licenses/by-nc/ 4.0/), which permits any noncommercial use, duplication, adaptation, distribution, and reproduction in any medium or format, as long as you give appropriate credit to the original author(s) and the source, a link is provided to the Creative Commons license, and any changes made are indicated. The images or other third party material in this chapter are included in the work's Creative Commons license, unless indicated otherwise in the credit line; if such material is not included in the work's Creative Commons license and the respective action is not permitted by statutory regulation, users will need to obtain permission from the license holder to duplicate, adapt, or reproduce the material. 